\title{
$R D L$ mutations in Guangxi Anopheles sinensis populations along the China-Vietnam border: distribution frequency and evolutionary origin of A296S resistance allele
}

\author{
Nian Liu' ${ }^{1,2}$, Xiangyang Feng ${ }^{3 *}$ and Xinghui Qiu ${ }^{1 *}(\mathbb{D}$
}

\begin{abstract}
Background: Malaria is a deadly vector-borne disease in tropical and subtropical regions. Although indigenous malaria has been eliminated in Guangxi of China, 473 confirmed cases were reported in the Northern region of neighbouring Vietnam in 2014. Considering that frequent population movement occurs across the China-Vietnam border and insecticide resistance is a major obstacle in disease vector control, there is a need to know the genotype and frequency of insecticide resistance alleles in Anopheles sinensis populations along the China-Vietnam border and to take action to prevent the possible migration of insecticide resistance alleles across the border.
\end{abstract}

Methods: Two hundred and eight adults of An. sinensis collected from seven locations in Guangxi along the ChinaVietnam border were used in the investigation of individual genotypes of the AsRDL gene, which encodes the RDL gamma-aminobutyric acid (GABA) receptor subunit in An. sinensis. PCR-RFLP (polymerase chain reaction-restriction fragment length polymorphism) analysis was deployed to genotype codon 345, while direct sequencing of PCR products was conducted to clarify the genotypes for codons 296 and 327 of the AsRDL gene. The genealogical relation of AsRDL haplotypes was analyzed using Network 5.0.

Results: Three putative insecticide resistance related mutations (A296S, V327I and T345S) were detected in all the seven populations of An. sinensis in Guangxi along the China-Vietnam border. The resistance-conferring A296S mutation was found to be widely distributed and present at notably high frequencies (78.8\% to 100\%). Relatively lower frequencies of mutations V327I (26.9\% to 53.2\%) and T345S (0\% to 28.8\%) were observed. The V327I or T345S always occurred in the presence of A296S. Evolutionary analysis of 21 AsRDL haplotypes indicated multiple origins of the A296S and V327I mutations.

Conclusion: The resistance A296S allele was present at high frequencies in the An. sinensis populations along the China-Vietnam border, indicating a risk of resistance to insecticides targeting RDL. The double mutations (A296S + V327I) may have evolved from alleles carrying the A296S mutation by scaffolding the additional mutation

\footnotetext{
*Correspondence: 13077712341@163.com; qiuxh@ioz.ac.cn

1 State Key Laboratory of Integrated Management of Pest Insects and Rodents, Institute of Zoology, Chinese Academy of Sciences, Beijing 100101, China

${ }^{3}$ Guangxi Zhuang Autonomous Region Centre for Diseases Control and Prevention, Nanning 530028, China

Full list of author information is available at the end of the article
}

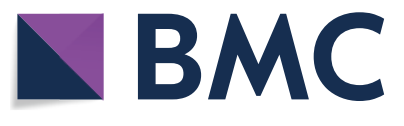

(c) The Author(s) 2020. This article is licensed under a Creative Commons Attribution 4.0 International License, which permits use, sharing, adaptation, distribution and reproduction in any medium or format, as long as you give appropriate credit to the original author(s) and the source, provide a link to the Creative Commons licence, and indicate if changes were made. The images or other third party material in this article are included in the article's Creative Commons licence, unless indicated otherwise in a credit line to the material. If material is not included in the article's Creative Commons licence and your intended use is not permitted by statutory regulation or exceeds the permitted use, you will need to obtain permission directly from the copyright holder. To view a copy of this licence, visit http://creativeco mmons.org/licenses/by/4.0/. The Creative Commons Public Domain Dedication waiver (http://creativecommons.org/publicdomain/ zero/1.0/) applies to the data made available in this article, unless otherwise stated in a credit line to the data. 
V327I, and A296S allele may have multiple evolutionary origins. These findings will help inform strategies for vector control and malaria prevention.

Keywords: Anopheles sinensis, Guangxi Zhuang Autonomous Region, China-Vietnam border, Insecticide resistance, RDL, Gamma-aminobutyric acid receptor

\section{Background}

Malaria is one of the most serious vector-borne diseases. Despite being preventable and treatable, malaria continues to be a major threat to global public health. In 2017, there were an estimated 219 million cases of malaria and 435,000 deaths from malaria globally, with $5 \%$ of the cases occurring in the WHO South-East Asia Region [1]. Guangxi Zhuang Autonomous Region of China was once a malaria-endemic region [2]. After continued efforts for decades, the malaria burden has been substantially reduced in Guangxi $[2,3]$. However, the risk of malaria re-emergence remains, due to the importation of malaria parasites in thousands of infected travellers from Africa, and Southeast Asia. In neighbouring Vietnam, the malaria incidence declined significantly between 1991 and 2014, but there were 14,941 confirmed cases in 2014, including 473 confirmed cases in the Northern region [4].

Insecticide-based vector control remains a key preventive strategy in the fight against malaria, credited with the significant reductions in malaria morbidity and mortality since 2000 due to the widespread implementation of insecticidal interventions [5]. However, the continued effectiveness of this strategy has been challenged by the increasing resistance of vectors to available insecticides. To minimize the risk of control failure caused by insecticide resistance, a better understanding of the status of and the genetic mechanisms underpinning resistance to commonly used insecticide is an urgent need.

In the previous study [6], the distribution and frequency of genetic mutations in two targets, acetylcholinesterase $(\mathrm{AChE})$ and the voltage-gated sodium channel (VGSC), were investigated. The G119S mutation within $\mathrm{AChE}$ was present at high frequencies (0.61-0.85), but the $k d r$ mutation was rare in the seven Guangxi $A n$. sinensis populations along the China-Vietnam border, suggesting that pyrethroids remain suitable for use against An. sinensis [6]. However, to maintain their effectiveness, the application of pyrethroids should not be taken as the sole measure for vector control, thus insecticides with alternative modes of action should be considered.

The current study was a survey extended to another insecticidal target, gamma-aminobutyric acid (GABA) receptor subunit encoded by the $R D L$ (Resistant to dieldrin) gene, which is the target of multiple types of insecticides, such as dieldrin (cyclodienes), fipronil (phenylpyrazoles), and fluralaner (isoxazolines) [7-9]. Efforts were given to detect naturally existing genetic mutations, map their distribution and frequency in seven $A n$. sinensis populations along the China-Vietnam border, and track the origin of the resistance-related mutations. This work focused on amino acid substitutions at three positions (A296G/N/S, V327I and M345M/S) in RDL that are associated with insecticide resistance previously documented in multiple insect species [8-13]. The data obtained in this study are of significance for current and future malaria control programs given that the use of GABA targeting insecticides is on the increase.

\section{Methods \\ Samples}

Anopheles sinensis adults were caught in seven different sites from April 2015 to August 2017. The seven samplecollecting sites were located in different villages along the China-Vietnam border. Rice is the main crop planted in these villages. The commonly used insecticides for rice pest control in these areas are diamides (e.g. chlorantraniliprole), neonicotinoids (e.g. imidacloprid) and organophosphorates (e.g. acephate and dimethoate). Methods about sample collection and species identification were described by Yang et al. [6].

\section{AsRDL genotyping}

A fragment of the AsRDL gene that includes codons 296 and 327 (named as RDL7) was amplified using primers (Primers ARE-7F and 7I-R, Table 1) and individual genomic DNA as template. The amplification reaction consisted of $25 \mu \mathrm{l}$ of $2 \times$ Taq PCR Master Mix, $0.2 \mu \mathrm{M}$ each primer, and 50-150 ng of DNA template in a total volume of $50 \mu$ l. The amplification was programmed as $95{ }^{\circ} \mathrm{C}$ for 5 min; 42 cycles of $95^{\circ} \mathrm{C}$ for $30 \mathrm{~s}, 62^{\circ} \mathrm{C}$ for

Table 1 Brief information about PCR

\begin{tabular}{llll}
\hline Primer name & Sequence & $\begin{array}{l}\text { Annealing } \\
\text { temperature } \\
\left({ }^{\circ} \mathbf{C}\right)\end{array}$ & $\begin{array}{l}\text { Amplicon } \\
\text { size (bp) }\end{array}$ \\
\hline ARE-7F & $\begin{array}{lll}\text { AGTTTGTACGTTCGATGG } \\
\text { GTTA }\end{array}$ & 62 & 476 \\
$7 \mathrm{I}-\mathrm{R}$ & $\begin{array}{l}\text { GGCAACAGTAAGCTATGT } \\
\text { CGA }\end{array}$ & \\
$8 \mathrm{~F}-1$ & ATAATCGCCCCGGATCACC & 56 & 167 \\
$8 \mathrm{R}-1$ & CCTGCTGCTTCTTCTGTTCC & & \\
\hline
\end{tabular}


$30 \mathrm{~s}, 72{ }^{\circ} \mathrm{C}$ for $70 \mathrm{~s}$; and $72{ }^{\circ} \mathrm{C}$ for $10 \mathrm{~min}$. PCR products were directly sequenced (TSINGKE Biotech, Beijing, China). For clone sequencing, three to ten clones were sequenced. The sequences from clone sequencing were cross-checked with those from direct PCR product sequencing to clarify the two haplotypes in each heterozygote.

Primers $8 \mathrm{~F}-1$ and $8 \mathrm{R}-1$ (Table 1) were used to amplify a fragment of $167 \mathrm{bp}$ covering codon 345 of the AsRDL gene (named as RDL8). The reaction mixture $(30 \mu \mathrm{l})$ included $2 \times$ Taq PCR MasterMix, $0.2 \mu \mathrm{M}$ each primer and 30-100 ng of genomic DNA. The reaction procedure was set as $95^{\circ} \mathrm{C}$ for $5 \mathrm{~min} ; 38$ cycles of $95^{\circ} \mathrm{C}$ for $30 \mathrm{~s}, 56^{\circ} \mathrm{C}$ for $30 \mathrm{~s}, 72{ }^{\circ} \mathrm{C}$ for $10 \mathrm{~s}$; and $72{ }^{\circ} \mathrm{C}$ for $10 \mathrm{~min}$. PCR products were digested with the restricted DNA digestion enzyme HpyCH4 III (New England Biolabs) (Fig. 1a) for $2 \mathrm{~h}$ in a total volume of $20 \mu \mathrm{l}$ according to the manufacturer's instruction. The digestion products were detected by $3 \%$ agarose gel electrophoresis. The genotype of each sample was identified based on the resulting gel profiles: one band of $167 \mathrm{bp}$ for homozygous TCG (SS), one band of combined $83 \mathrm{bp}$ and $84 \mathrm{bp}$ for homozygous ACG (TT) (complete digestion of the 167 bp DNA by HpyCH4 III resulted in two fragments with a length of $83 \mathrm{bp}$ and 84 bp respectively, which could not be distinguished on a routine agarose gel); two bands (167 bp $+83 \mathrm{bp})$ for $\mathrm{T} /$ ACG (S/T) heterozygote (Fig. 1b).

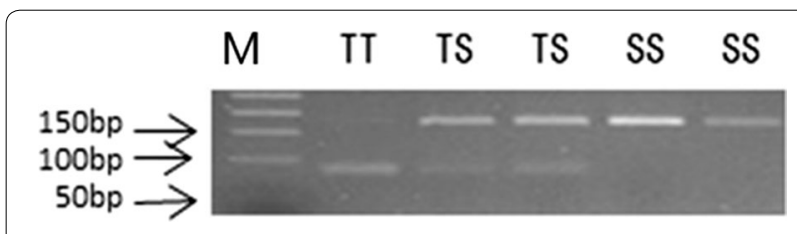

Fig. 1 Diagnostic PCR-RFLP tests to detect the T345S mutation. The 167 bp amplicon is undigested by HpyCH4 III for homozygous TCG (mutant 345SS), and cut into two fragments of $83 \mathrm{bp}$ and $84 \mathrm{bp}$ for homozygous ACG (wild 345TT) that co-migrate in the agarose gel and cannot be distinguished. A combined pattern (two bands $167 \mathrm{bp}+83 / 84 \mathrm{bp}$ ) is displayed for heterozygotes

\section{Data analysis}

Each sequencing result of RDL7 was manually checked and the terminal ambiguous regions were trimmed. All the confirmed sequences (360 bp) were aligned using Muscle 3.8 [14], and the polymorphic sites in the sequence were recorded. Hardy-Weinberg equilibrium (HWE) of genotypes in each population was tested by probability test using the online software GENEPOP v.4.2 [15]. The haplotypes of heterozygotes were clarified by clone sequencing. Haplotype network analysis was conducted using Network 5.0 [16].

\section{Results}

Nucleotide variations in the RDL7 region of the AsRDL gene Ten polymorphic sites (PS) were observed in RDL7 in a total length of $360 \mathrm{bp}$, three PSs in exon 7 and seven in intron 7 (Fig. 2). The 2nd and 3rd PSs represented synonymous mutations, causing amino acid substitutions at sites 296 (A296S) and 327 (V327I), respectively.

\section{Distribution and frequency of insecticide resistance-related mutations}

The distribution and frequency of the three insecticide resistance-related mutations are shown in Table 2 and Fig. 3. Overall, the frequency of A296S was very high (79-100\%) in the seven examined populations. Notably, this allele was fixed in four of the seven populations. By contrast, the frequency of the susceptible allele was rare: A296 was only detected in three populations (PXSS, JXTD, JXXW) at frequencies ranging from 1.5 to $21 \%$.

The three possible genotypes for site 327 were detected in all the seven populations, and all genotypes agreed with Hardy-Weinberg equilibrium (Table 2). The frequency of the mutant 327I ranged from 26.9 to $53.2 \%$ (Fig. 3). The mutant allele (345S) was detected in five of the seven populations, but absent in DXEC and CZSK. Overall, the frequency of $345 \mathrm{~S}$ was low $(0-28.8 \%)$, with the highest frequency being observed in FCGDX (Fig. 3).

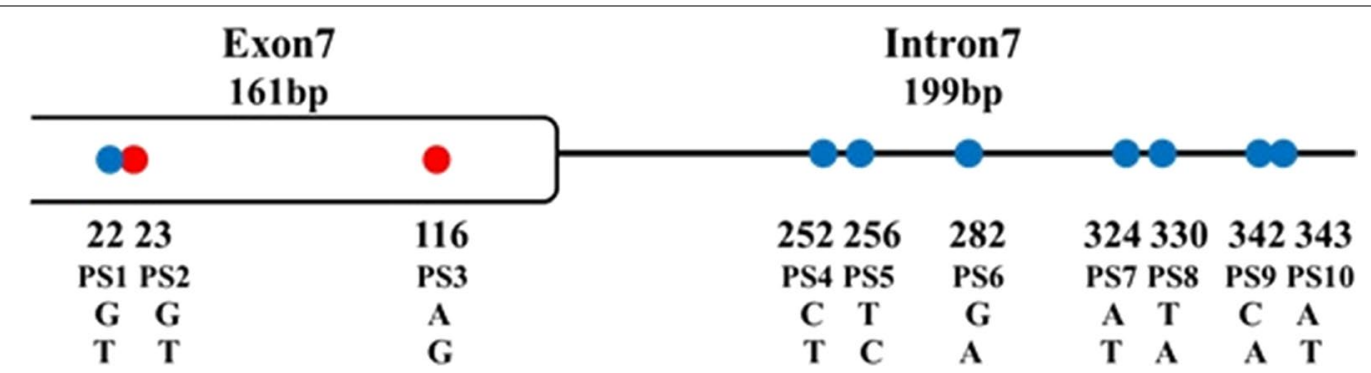

Fig. 2 The polymorphic sites identified in the $A s R D L$ gene in this study. Non-synonymous sites are indicated by red dots 
Table 2 Frequency of $R D L$ genotypes in seven An. sinensis populations along the China-Vietnam border

\begin{tabular}{|c|c|c|c|c|c|c|c|c|c|c|c|c|c|}
\hline \multirow[t]{2}{*}{ Population } & \multirow[t]{2}{*}{$\mathrm{n}$} & \multicolumn{3}{|c|}{ Residue 296 genotype } & \multirow[t]{2}{*}{ HWE test } & \multicolumn{3}{|c|}{ Residue 327 genotype } & \multirow[t]{2}{*}{ HWE test } & \multicolumn{3}{|c|}{ Residue 345 genotype } & \multirow[t]{2}{*}{ HWE test } \\
\hline & & $\overline{A A}$ & AS & SS & & $\mathrm{VV}$ & VI & II & & $\mathrm{TT}$ & TS & SS & \\
\hline DXEC & 31 & 0 & 0 & 31 & - & 6 & 17 & 8 & 0.4792 & 30 & 1 & 0 & - \\
\hline FCGDX & 33 & 0 & 0 & 33 & - & 9 & 13 & 11 & 0.2956 & 18 & 11 & 4 & 0.3905 \\
\hline JXTD & 27 & 1 & 3 & 23 & 0.1856 & 8 & 13 & 6 & 0.7069 & 20 & 6 & 1 & 0.4544 \\
\hline JXXW & 26 & 3 & 5 & 18 & 0.1984 & 15 & 8 & 3 & 0.3196 & 26 & 0 & 0 & - \\
\hline LZSK & 31 & 0 & 0 & 31 & - & 14 & 14 & 3 & 0.4602 & 31 & 0 & 0 & - \\
\hline NPPM & 28 & 0 & 0 & 28 & - & 8 & 15 & 5 & 0.7012 & 17 & 10 & 1 & 1.0000 \\
\hline PXSS & 32 & 0 & 1 & 31 & - & 15 & 12 & 5 & 0.4321 & 18 & 13 & 1 & 0.6416 \\
\hline
\end{tabular}

HWE Hardy Weinberg equilibrium

The values are $\mathrm{p}$ value by the probability test. $\mathrm{n}=$ sample size. The abbreviations for the sampling location are given in Fig. 3
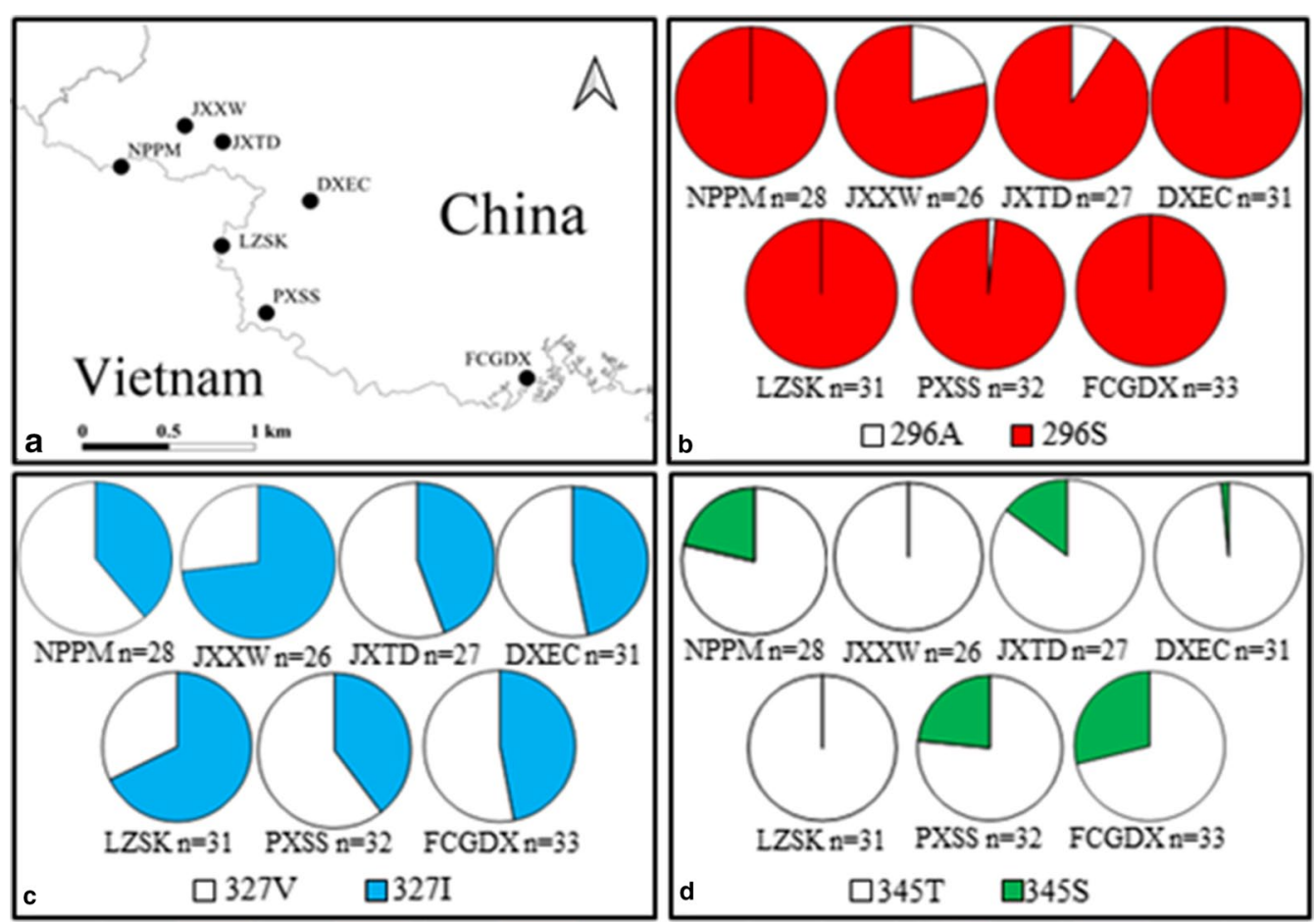

Fig. 3 The sampling location (a), and distribution frequencies of AsRDL allele (b-d). NPPM Pingmeng, Napo County; JXXW Xinwei, Jingxi County; JXTD Tongde, Jingxi County; DXEC Encheng, Daxin County; LZSK Shuikou, Longzhou County, PXSS Shangshi, Pingxiang County; FCGDX Dongxing town, Fangchenggang City

\section{Frequency and distribution of triple-locus genotype} combinations

When considering the three resistance-related sites together, 11 types of triple-locus genotypes (C1 to $\mathrm{C} 11$ ) were observed (Table 3). The number of triple-locus genotype combinations observed in each sampling site ranged from 3 (CZSK) to 9 (JXTD). Three combinations $(C 1, C 4, C 8)$ were distributed in all the seven populations, while $\mathrm{C} 6$ and $\mathrm{C} 7$ were uniquely found in PXSS and FCGDX, respectively. The triple-locus wild genotype (C11) was distributed in JXTD and JXXW. The alleles carrying 327I were found only in individuals that harbor $296 \mathrm{~S}$, and $345 \mathrm{~S}$ existed in individuals that were homozygous for 296S. Notably, the triple-locus mutant allele was detected (C6 and C7), although at low frequencies. 
Table 3 Distribution and frequency of triple-locus genotype combinations in seven An. sinensis populations along the China-Vietnam border

\begin{tabular}{|c|c|c|c|c|c|c|c|c|c|c|}
\hline \multirow[t]{2}{*}{ Combination } & \multicolumn{3}{|c|}{ Residue sites } & \multicolumn{7}{|c|}{ Frequency } \\
\hline & 296 & 327 & 345 & DXEC & FCGDX & JXTD & JXXW & LZSK & NPPM & PXSS \\
\hline $\mathrm{Cl}$ & SS & W & $\mathrm{TT}$ & 0.194 & 0.030 & 0.074 & 0.308 & 0.452 & 0.107 & 0.188 \\
\hline C2 & SS & W & TS & & 0.121 & 0.074 & & & 0.143 & 0.250 \\
\hline C3 & SS & W & SS & & 0.121 & 0.036 & & & 0.036 & \\
\hline C4 & SS & $\mathrm{Vl}$ & $\mathrm{TT}$ & 0.516 & 0.212 & 0.300 & 0.269 & 0.452 & 0.321 & 0.188 \\
\hline C5 & SS & $\mathrm{Vl}$ & TS & 0.032 & 0.182 & 0.148 & & & 0.214 & 0.156 \\
\hline C6 & SS & $\mathrm{Vl}$ & SS & & & & & & & 0.031 \\
\hline C7 & SS & $\|$ & TS & & 0.031 & & & & & \\
\hline C8 & SS & $\|$ & $\mathrm{TT}$ & 0.258 & 0.303 & 0.222 & 0.115 & 0.096 & 0.179 & 0.156 \\
\hline C9 & AS & W & $\mathrm{TT}$ & & & 0.074 & 0.155 & & & 0.031 \\
\hline $\mathrm{C} 10$ & AS & $\mathrm{Vl}$ & $\mathrm{TT}$ & & & 0.036 & 0.038 & & & \\
\hline C11 & AA & W & $\mathrm{TT}$ & & & 0.036 & 0.115 & & & \\
\hline
\end{tabular}

Table 4 RDL haplotypes in seven An. sinensis populations along the China-Vietnam border

\begin{tabular}{|c|c|c|c|c|}
\hline $\begin{array}{l}\text { Haplotype } \\
\text { name }\end{array}$ & GenBank ID & $\begin{array}{l}\text { Polymorphic } \\
\text { sites }\end{array}$ & Residue 296 & Residue 327 \\
\hline $\mathrm{H} 1$ & MK686613 & TGGTCGTTCA & A & V \\
\hline $\mathrm{H} 2$ & MK686614 & TGGTCGATCA & A & V \\
\hline $\mathrm{H} 3$ & MK686615 & TGGTCGATCT & A & V \\
\hline $\mathrm{H} 4$ & МK686616 & TGGCCGATCT & A & V \\
\hline $\mathrm{H} 5$ & MK686617 & GTGITGAAAT & S & V \\
\hline $\mathrm{H} 6$ & MK686618 & GTGTCGATAT & S & V \\
\hline $\mathrm{H} 7$ & МK686619 & GTGTCGAAAA & S & V \\
\hline $\mathrm{H} 8$ & MK686620 & GTGTCGAAAT & S & V \\
\hline $\mathrm{H} 9$ & MK686621 & TTGTCAATCT & S & V \\
\hline $\mathrm{H} 10$ & MK686622 & TTGTCGATCT & S & V \\
\hline $\mathrm{H} 11$ & МK686623 & GTGTTGATCA & S & V \\
\hline $\mathrm{H} 12$ & MK686624 & GTGTCGATCA & S & V \\
\hline $\mathrm{H} 13$ & MK686625 & TTGICGATCA & S & V \\
\hline $\mathrm{H} 14$ & MK686626 & TTGTCGATAT & S & V \\
\hline $\mathrm{H} 15$ & MK686627 & TTGTCGAAAT & S & V \\
\hline $\mathrm{H} 16$ & MK686628 & TTATTAATCA & $S$ & 1 \\
\hline $\mathrm{H} 17$ & MK686629 & GTATTGAAAT & S & 1 \\
\hline $\mathrm{H} 18$ & MK686630 & TTATCGAAAT & S & 1 \\
\hline H19 & MK686631 & TTATCGATCA & S & 1 \\
\hline $\mathrm{H} 2 \mathrm{O}$ & MK686632 & TTATCGATAA & S & 1 \\
\hline $\mathrm{H} 21$ & MK686633 & TTATCGATCT & S & I \\
\hline
\end{tabular}

The polymorphic sites in intron 7 are underlined

\section{Evolutionary origin of $296 \mathrm{~S}$ and 327}

To track the possible origin of mutant $296 \mathrm{~S}$ and 327I, the DNA sequences of 360 bp-in-length (Fig. 2) were used for haplotype identification and network analysis. A total of 21 haplotypes ( $\mathrm{H} 1$ to H21) were identified (Table 4).
Among them, 4 (H1 to $\mathrm{H} 4)$ were wild haplotypes without $296 \mathrm{~S}$ and 327I mutations, 11 (H5-H15) were haplotypes with only the 296S mutation, and 6 (H16-H21) carried both $296 \mathrm{~S}$ and 327I mutations. The 327I mutation was found always together with 296S. Network analysis indicated that the $296 \mathrm{~S}$ allele might have evolved independently from more than one origin (Fig. 4). The single mutation haplotypes H13 and H10 may be evolved from $\mathrm{H} 2$ and $\mathrm{H} 3$, respectively, while the five double-mutation haplotypes (H17-H21) could be derived from some $296 \mathrm{~S}$ haplotypes via only one mutational step (Fig. 4).

\section{Discussion}

Point mutations (A to $\mathrm{S} / \mathrm{G} / \mathrm{N}$ ) at the site equivalent to 301 in Drosophila (site 296 of AsRDL) in the second transmembrane domain of RDL have been documented in diverse insecticide-resistant insects [10-12, 17-19]. In this study, the resistant mutation $296 \mathrm{~S}$ was detected and its frequency was very high $(79-100 \%)$ in the seven examined populations, suggesting a strong risk of resistance to GABA targeting insecticides in these mosquito populations. The prevalence of mutation at 296 was also detected in An. sinensis collected in other locations of Guangxi [13], and in Anopheles funestus in Africa [12]. Given that the use of cyclodienes has been banned, the high level of $296 \mathrm{~S}$ in An. sinensis in Guangxi may be a consequence of the increasing use of insecticides targeting the GABA receptor (e.g. ethiprole, fipronil) in the agriculture [20], or selection pressures by organochlorine pesticides from unknown origins. Another explanation may be that A296S substitution has no fitness cost under current natural conditions, or the cost mediated by A296S is alleviated by unknown fitness modifiers. 


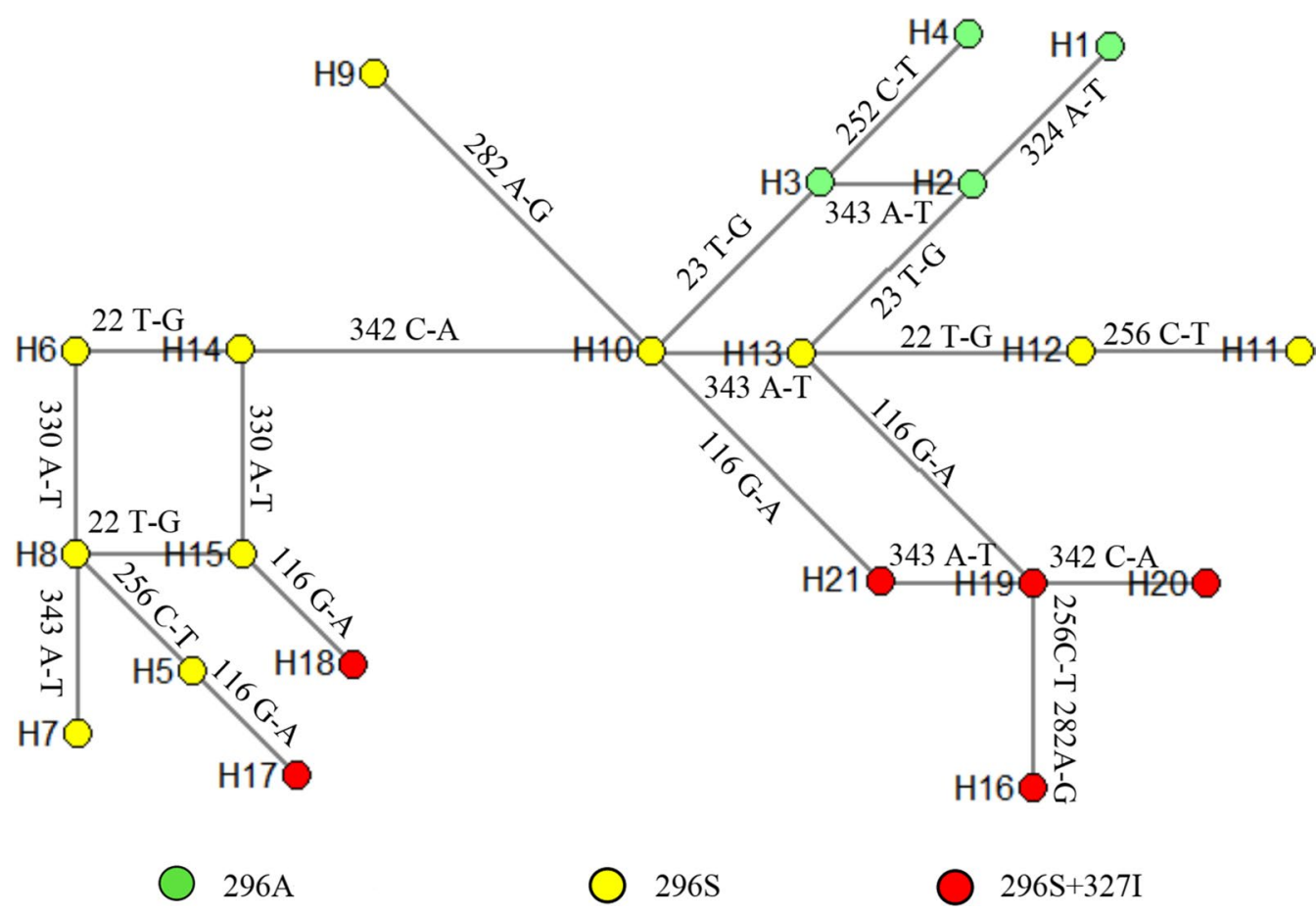

Fig. 4 The network of RDL haplotypes identified in An. sinensis populations along the China-Vietnam border

Two mutations (V327I and T345S) previously detected in another nine An. sinensis populations from Guangxi [13] were also found in the current study. Interestingly, either 327I or $345 \mathrm{~S}$ was present together with $296 \mathrm{~S}$. The 327I mutation was also previously identified in dieldrinresistant An. funestus [12]. Similarly, a conserved mutation at the equivalent site of RDL was also reported in Anopheles gambiae (T345M) [8] and Drosophila $(\mathrm{T} 350 \mathrm{M} / \mathrm{S})[21,22]$. Although the two conserved mutations have been suggested to play a role in insecticide resistance when they occurs together with an amino acid substitution at the site 296 [12, 22], their impact on the pharmacology of the GABA receptor and contribution to insecticide resistance remains unclear. This would be an interesting question worthy of study.

Network analysis does not support single origin of the resistance-conferring 296S mutation and the related 327I mutation in AsRDL. The two wild A296 haplotypes (H1 and $\mathrm{H} 4$ ) could be considered as two possible ancestors of resistant 296S haplotypes identified in this study (Fig. 4). Multiple origins of $345 \mathrm{~S}$ were also inferred in the previous study [13].

\section{Conclusion}

A PCR-RFLP diagnostic assay was developed to genotype the T345S mutation in the AsRDL gene. Three previously reported mutations (A296S, V327I and T345S) were detected in the seven An. sinensis populations in Guangxi along the China-Vietnam border. The prevalence of the resistance-related A296S mutation within An. sinensis populations along the China-Vietnam border indicates a risk of resistance to insecticides targeting the GABA receptor, such as dieldrin and fipronil. The resistance A296S allele may have multiple evolutionary origins, and the double mutations (A296S + V327I) may have evolved from alleles carrying the A296S mutation by scaffolding the additional mutation V327I.

\section{Abbreviations}

GABA: gamma-aminobutyric acid; Guangxi: Guangxi Zhuang Autonomous Region, China; HWE: Hardy-Weinberg equilibrium; PCR: polymerase chain reaction; RFLP: restriction fragment length polymorphism; RDL: resistant to dieldrin.

\section{Acknowledgements}

The authors would thank Dr. Chan Yang for DNA preparation, and Ms. Mei Li for technical support.

\section{Authors' contributions}

$X H Q$ and XYF conceived the study. NL performed the experiment. NL and XHQ analyzed the data. NL, XHQ and XYF wrote the paper. XYF contributed to sample collection. All authors read and approved the final manuscript.

\section{Funding}

This work was supported by the National Science and Technology Major Project of China on Infectious Diseases (No. 2017ZX10303404). The funders had no role in the study design, data collection, analysis, decision to publish or preparation of the manuscript. 


\section{Availability of data and materials}

All the datasets are presented in the main paper. The newly generated sequences were submitted to the GenBank database under the accession numbers MK686613-MK686633.

\section{Ethics approval and consent to participate}

Not applicable.

\section{Consent for publication}

Not applicable.

\section{Competing interests}

The authors declare that they have no competing interests.

\section{Author details}

1 State Key Laboratory of Integrated Management of Pest Insects and Rodents, Institute of Zoology, Chinese Academy of Sciences, Beijing 100101, China. ${ }^{2}$ Institute of Physical Science and Information Technology, Anhui University, Hefei 230039, China. ${ }^{3}$ Guangxi Zhuang Autonomous Region Centre for Diseases Control and Prevention, Nanning 530028, China.

Received: 17 April 2019 Accepted: 7 January 2020

Published online: 15 January 2020

\section{References}

1. WHO. World malaria report 2018. Geneva: World Health Organization; 2018

2. Li JH, Li J, Qin YX, Guo CK, Huang YM, Lin Z, et al. Appraisal of the effect and measures on control malaria for 60 years in Guangxi. J Trop Med. 2014;14:361-4.

3. Li JH, Wei SJ, Yang YC, Li J. Analysis of the prevalence of imported malaria in Guangxi from 2012 to 2013. J Pathog Biol. 2015;10:180-3.

4. Goldlust SM, Thuan PD, Giang DDH, Thang ND, Thwaites GE, Farrar J, et al. The decline of malaria in Vietnam, 1991-2014. Malar J. 2018;17:226.

5. WHO. Global technical strategy for malaria 2016-2030. Geneva: World Health Organization; 2016.

6. Yang C, Feng X, Liu N, Li M, Qiu X. Target-site mutations (AChE-G119S and $k d r)$ in Guangxi Anopheles sinensis populations along the China-Vietnam border. Parasit Vectors. 2019;12:77.

7. Casida JE, Durkin KA. Novel GABA receptor pesticide targets. Pestic Biochem Physiol. 2015;121:22-30.

8. Taylor-Wells J, Brooke BD, Bermudez I, Jones AK. The neonicotinoid imidacloprid, and the pyrethroid deltamethrin, are antagonists of the insect Rdl GABA receptor. J Neurochem. 2015:135:705-13.

9. Buckingham S, Ihara M, Sattelle DB, Matsuda K. Mechanisms of action, resistance and toxicity of insecticides targeting GABA receptors. Curr Med Chem. 2017;24:2935-45.
10. Ffrench-Constant RH, Rocheleau TA, Steichen JC, Chalmers AE. A point mutation in a Drosophila GABA receptor confers insecticide resistance. Nature. 1993:363:449-51.

11. Du W, Awolola TS, Howell P, Koekemoer LL, Brooke BD, Benedict MQ, et al. Independent mutations in the RdI locus confer dieldrin resistance to Anopheles gambiae and Anopheles arabiensis. Insect Mol Biol. 2005; 14:179-83.

12. Wondji CS, Dabire RK, Tukur Z, Irving H, Djouaka R, Morgan JC. Identification and distribution of a GABA receptor mutation conferring dieldrin resistance in the malaria vector Anopheles funestus in Africa. Insect Biochem Mol Biol. 2011;41:484-91.

13. Yang C, Huang Z, Li M, Feng X, Qiu X. RDL mutations predict multiple insecticide resistance in Anopheles sinensis in Guangxi, China. Malar J. 2017:16:482.

14. Edgar RC. MUSCLE: multiple sequence alignment with high accuracy and high throughput. Nucleic Acids Res. 2004;32:1792-7.

15. Rousset F. GENEPOP '007: a complete re-implementation of the GENEPOP software for Windows and Linux. Mol Ecol Resour. 2008;8:103-6.

16. Bandelt $H$, Forster $P$, Rohl A. Median-joining networks for inferring intra specific phylogenies. Mol Biol Evol. 1999:16:37-48.

17. Nakao T, Kawase A, Kinoshita A, Abe R, Hama M, Kawahara N, et al. The $\mathrm{A} 2^{\prime} \mathrm{N}$ mutation of the RDL $\gamma$-aminobutyric acid receptor conferring fipronil resistance in Laodelphax striatellus (Hemiptera: Delphacidae). J Econ Entomol. 2011;104:646-52.

18. Nakao T. Mechanisms of resistance to insecticides targeting RDL GABA receptors in planthoppers. Neurotoxicology. 2017;60:293-8.

19. Wei Q, Wu SF, Gao CF. Molecular characterization and expression pattern of three GABA receptor-like subunits in the small brown planthopper Laodelphax striatellus (Hemiptera: Delphacidae). Pestic Biochem Physiol. 2017;136:34-40.

20. Wang Y, Wang M. Factors affecting the outbreak and management tactics of brown planthopper in China recent years. Pestic Sci Adm. 2007;25:49-54.

21. Le Goff G, Hamon A, Berge J-B, Amichot M. Resistance to fipronil in Drosophila simulans: influence of two point mutations in the RDL GABA receptor subunit. J Neurochem. 2005;92:1295-305.

22. Remnant EJ, Morton CJ, Daborn PJ, Lumb C, Yang YT, Ng HL, et al. The role of $\mathrm{Rdl}$ in resistance to phenylpyrazoles in Drosophila melanogaster. Insect Biochem Mol Biol. 2014;54:11-21.

\section{Publisher's Note}

Springer Nature remains neutral with regard to jurisdictional claims in published maps and institutional affiliations.
Ready to submit your research? Choose BMC and benefit from:

- fast, convenient online submission

- thorough peer review by experienced researchers in your field

- rapid publication on acceptance

- support for research data, including large and complex data types

- gold Open Access which fosters wider collaboration and increased citations

- maximum visibility for your research: over 100M website views per year

At BMC, research is always in progress.

Learn more biomedcentral.com/submissions 